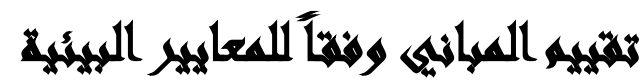

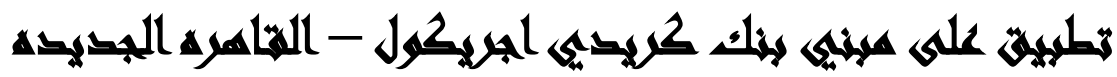

[६]

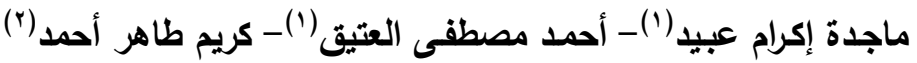

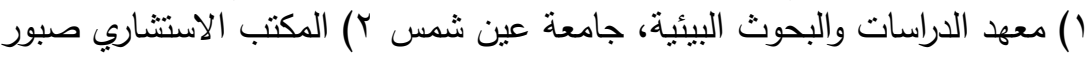

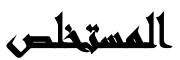

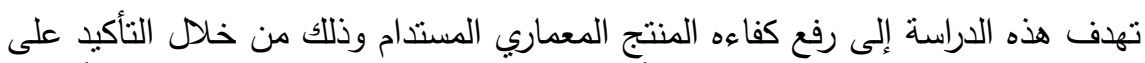

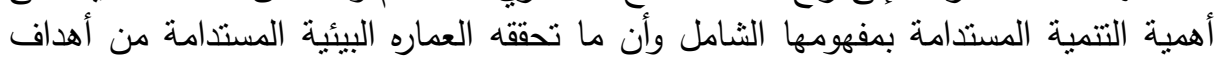
التتمية المستدامة بنعكس اثره على مسار التتمية.

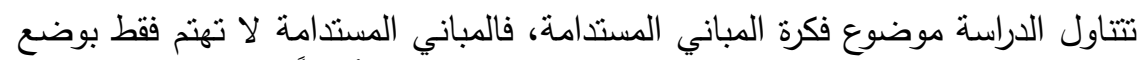

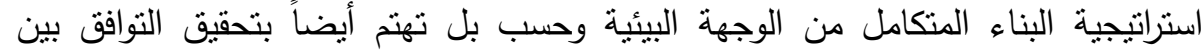

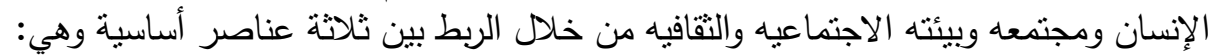

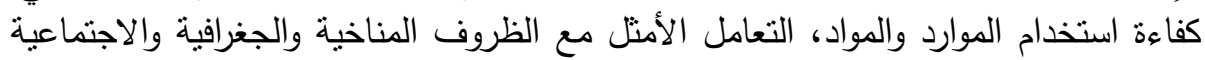

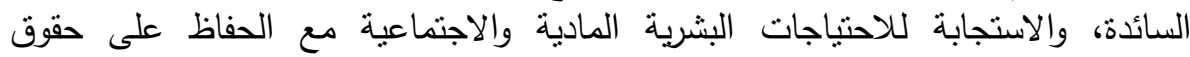
واحتياجات الأجيال القادمة. الكلمات الافتتاحية: نظم التقييم البيئية - المعايير البيئية - العمارة المستدامة - الاعتبارات الانسانية في التصميم الافتاحيم

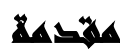

" نحو تتمية مستدامة " ارتفعت الكثثر من الاصوات في الآونه الاخيره بتلك العباره

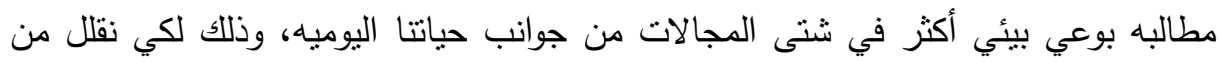
المشاكل البيئيه الحالية والتى سببها الانسان وللحد من الاستتزاف المستمر لموارد البيئه الطبيعيه مما سيؤدي الى توفير بيئه صحيه مستدامه للاجيال القادمه.

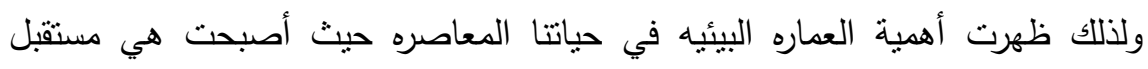
العماره بشكل عام، ومن هنا فتقييم ددى نجاحها في تحقيق أهدافها لهو ضروري وهام وهام للغايه

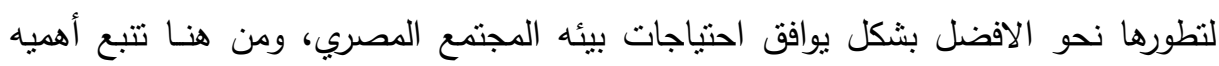
تقييم مستوى أداء المباني بشكل عملى وموضوعي لا يعتمد على الاهواء أو التفضيلات

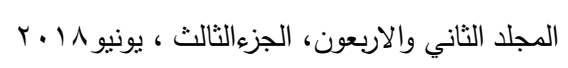


الثخصية ولكن يجب أولاً أن يكون التقييم بشكل متكامل وفقاً للبيئه المحليه للمجتمع المصري

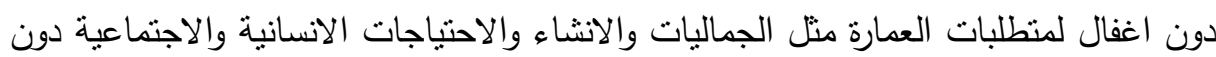
اغفال للمعايير البيئيه الدوليه.

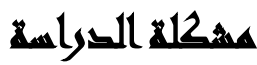

تكمن الاشكالية الرئيسية للاراسة في أن العالم الان يتجه نحو معايير بيئية جديدة تحكم

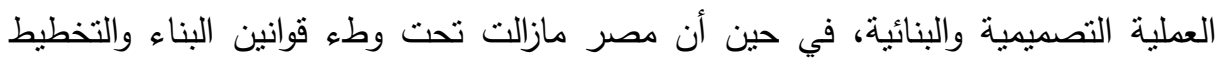

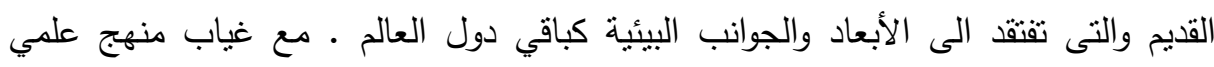
واضح لرصد وتقييم الاليات الخاصة بالاطراف الرئيسية المشاركه في العملية التصميمية

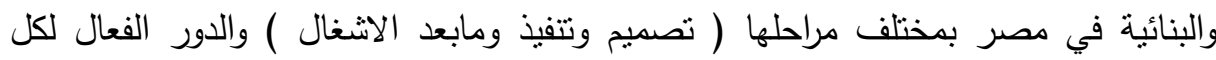
طرف في التتسيق لتحقيق الاهداف البيئية والاجتماعية والثقافية والاقتصادية في عمران المجتمع المصري. يتمثل السؤال الرئيسي للاراسة في: ما هي الأبعاد الاجتماعية والثقافية والنفسيه في مصر

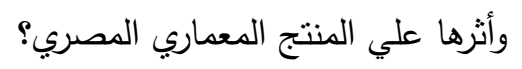

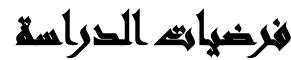

تقوم الدراسة علي فرضية ان المنتج المعماري هو نتاج بنائي للأطراف الششاركه في

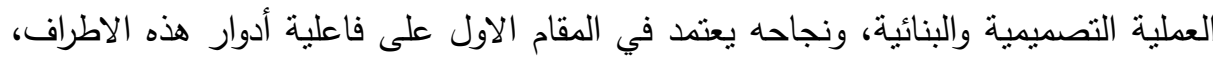
وكذلك تتفاعل بعض العوامل والمؤثرات لضمان نجاح الظاهره الانمائية.

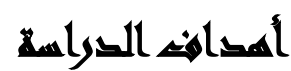

تهدف الدراسة الى التأكيد على ارساء قواعد وأسس لدراسات نقييم المباني في مصر في ضوء الابعاد الاجتماعية والثقافية الخاصة بالمجتمع المصري وهويته وتمهيد الطريق الى مزيد من منل هذه الدراسات التقييمية المختلفة للحصول على مسنويات عالية من الاداء البيئي 
للمباني وبالتالى تأتى التصميمات أكثر ملائمة للواقع المحلى وملبية للاحتياجات الاجتماعية والانسانية والثقافة ومحققة لمسنويات عالية من كفاءه الاداء من الناحية البيئية المصرية .

\section{أهمه التواسم}

تتبع أهمية هذا الدراسة من خلال ان تلك المعايير أصبحت شيء مطبق في كافة الدول

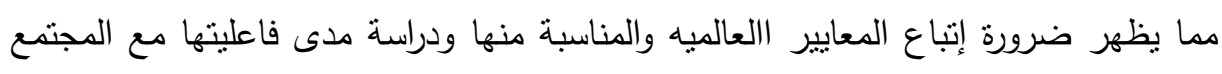
المصري.

\section{منهمير التصواسمة}

المنهج المنبع هنا هو المنهج الوصفي من خلال أسلوب الاستتباط الذي يقوم على

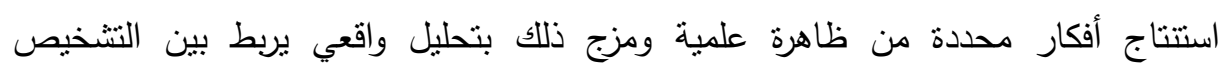
والمعالجات من جهة والواقع من جهة أخرى.

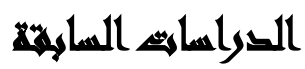

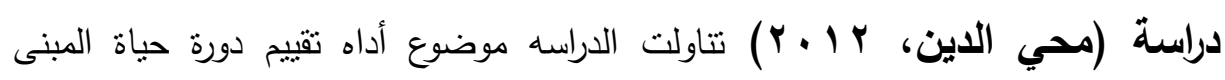
النموذج الدولى وتطبيقه في مصر حيث يقوم البحث بتطبيق اداه التقييم للنموذج الدولى ذات الهيكل الموحد على مصر كمثال على امكانية استيفاء الاحتباجات المحلية للمناطق المختلفه

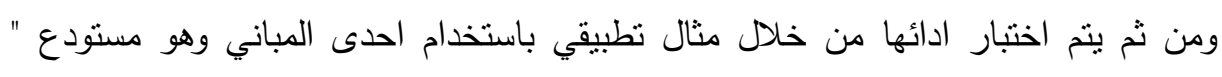

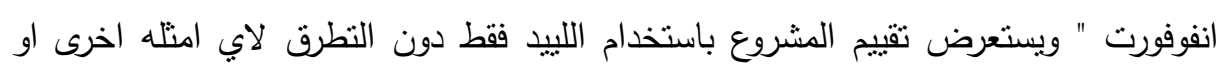

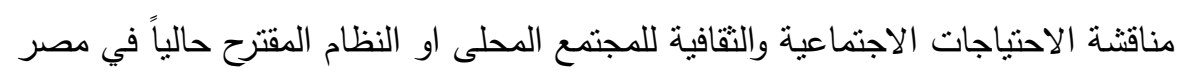
دراسة (محمد، 9 . . r) تتاولت مدخل لفاعلية تطبيق مبدأ المباني المستدامة من خلال منهجية هندسة القيمة وتكلفة دوره الحياه بدراسة تطبيق مبادىء العماره المستدامة من خلال تحقيق منهجية مايسمى بالهندسة القيمة وتحليل دوره حياه المبنى للوقوف على منهجيه سليمه لئه

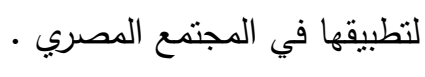

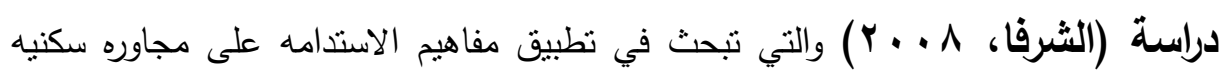
بقطاع غزه فقد تتاول البحث مفهوم الاستدامة وتاريخ نثأتها والمفهوم المتأصل للاستدامة في في فئري

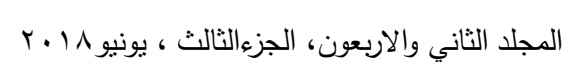


الإسلام من خلال دراسة العلاقة بين الإنسان والبيئة دون اهمال الجانب الاقتصادي والاجتماعي، وليس بمعزل عن الواقع البيئي ودراسه مستويات التخطبط بتدريجاته الهرمية،

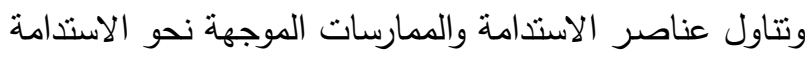

\section{التحليل}

الغرض الأساسي من العمل المعماري هو تهيئة الفراغ والبيئة المحيطة لراحة الإنسان النفسية والبدنية والفكرية أثناء تأديته للأنشطة المختلفة في مراحل حياته وباختلاف أجناسه، وينقسم العمل المعماري إلى أقسام رئيسية تعكس مجموعة الأهداف التي يجب لستبة استيفائها في

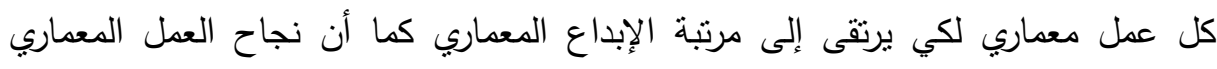

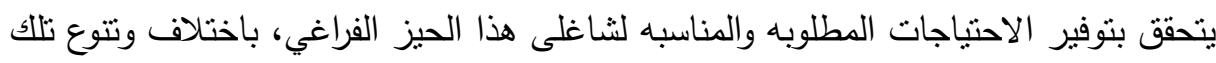

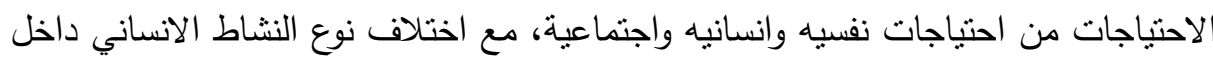
• الفراغ المحاور الاساسيه لاراسه مشروع البحث : اعتمدت الدراسه على ثلاث محاور أساسيه

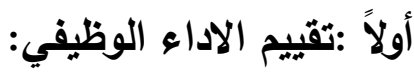
• طبيعه الموقع وعناصر التنسيق الخارجي أهميه المشروع - البعد او القرب من وسائل المواصلات - مسطح المبني / الارض - نتوجيه المبني - المسطحات الخضراء -

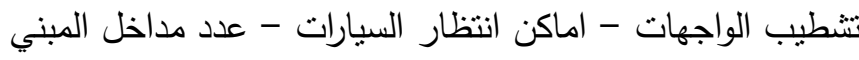

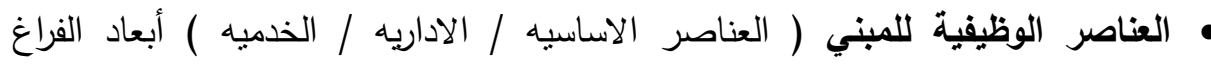
الرئيسي - النتطيب الداخلي - توجيه الفرا غات • العناصر التكميليه للمبني الثبابيك - وحدات الاضاءه - التركيبات الصحيه - المصاعد ثانياً :تقييم الاحتياجات الانسانية:

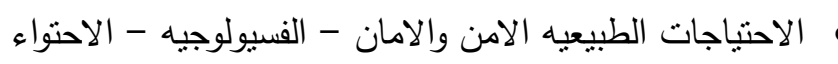

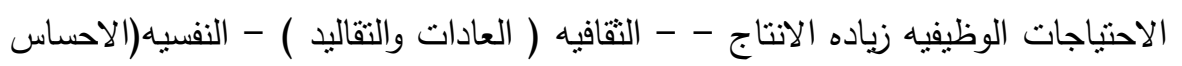
(بالجمال) 
ثنالثاً: تقييم الأداء البيئي: الموقع المستدام - كفاءه استخدام المياه - الطاقه والمناخ -

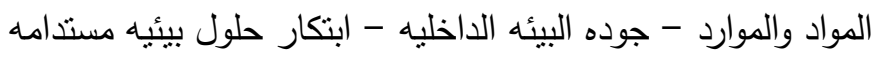

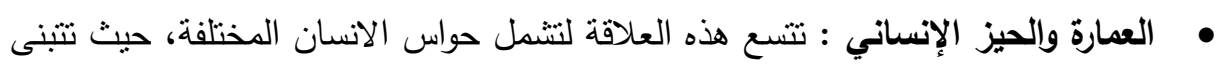

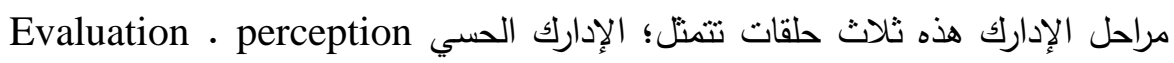
والتقييم، Cognition والإدارك المعرفي، فينبغي على العمارة نوفير محيط ملائم لتتكيل السلوك من خلال تبادل المشاعر الطيبة مع الآخرين وتحقيق مستوى من الحاجات النفسية

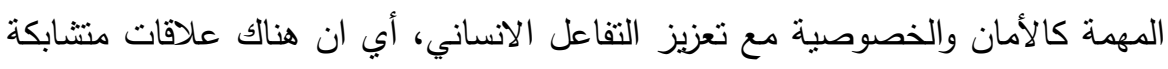

بين الفضاءات المعمارية والفعاليات البشرية فان تغير احدهما يترتب عليه تغير الثانية.

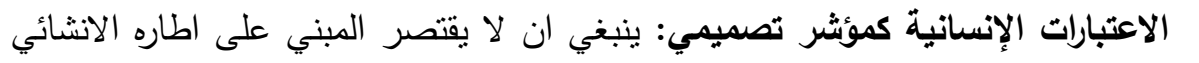

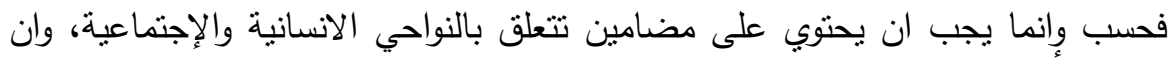

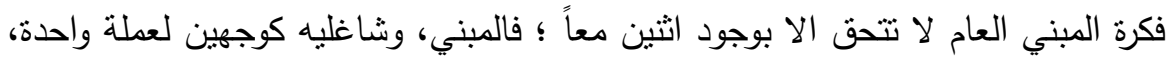

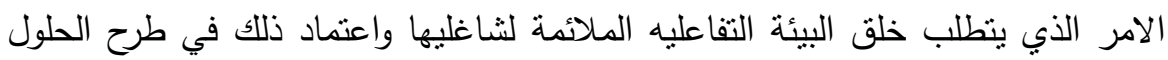
والبدائل التصميمية للبيئة المشيده بشكل عام والتي تُعنى باتخاذ الاعتبارات الإنسانية مؤشراً تصميمياً للعمارة بشقيها؛ الوظيفي النفعي، والحسي التعبيري، تجاه ما ما يكفل استتفائه

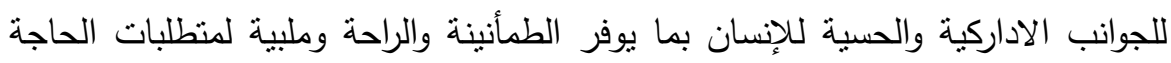

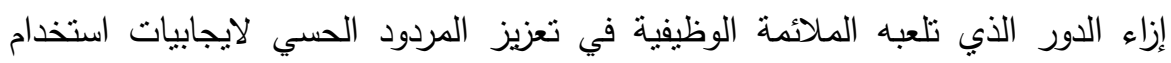
الفضاء المعماري وملائمة صباغة العناصر التشكيلية للمعطيات المناخية. وملائمة صياغة عناصر التشكيل للمعطيات البيئية، وملائمة الصياغة الوظيفية لمختلف العناصر لنقافة المستخدم من جانب، وفرضيات الواقع الثقافي من جانب أخر ويمكن ايجاز الاعتبارات الانسانية في التصميم في الآتي:

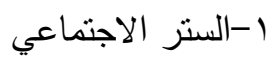
r-توثيق العلاقات الاجتماعية: أ) تكوين الصداقات ب) تكوين مجموعات r-الحيز الثخصي لتهي ع-الذاتية الثخصية ه-الملكية 


$$
\begin{aligned}
& \text { 4-الاتصالات } \\
& \text { V-الاستكثاف الموجه } \\
& \text { ^-الأمن الثخصي } \\
& \text { 9-الحرارة الاجتماعية الحندية } \\
& \text { ـ } 1 \text {-الارتباط بالطبيعة }
\end{aligned}
$$

وقد طرحت هذه الدراسة ضرورة نوفير الاحتياجات السلوكية والنفسية للإنسان والمتعلقة بالفراغات الداخلية، وذللك في مرحلة التصميم لتلك الفراغات، ويكون ذلك عن طريق التعرف على الاحتياجات وتصنيفها ودراسة مكونات الفراغ، ومحاولة الربط بينهما بلغة من التحاور الرمزي وغير الثفهي، ومحاولة الربط هذه تسعى إلى تجميع كل من المصمم والمستعمل وعلماء الاجتماع والنفس وتظهر الاسكتشات في الثكل النالي استغلال الفراغات البينيه بين المباني لتحقيق بعض الاحتياجات الاجتماعيه لسكان هذه العمائر وتوفير سبل التواصل والاتصال
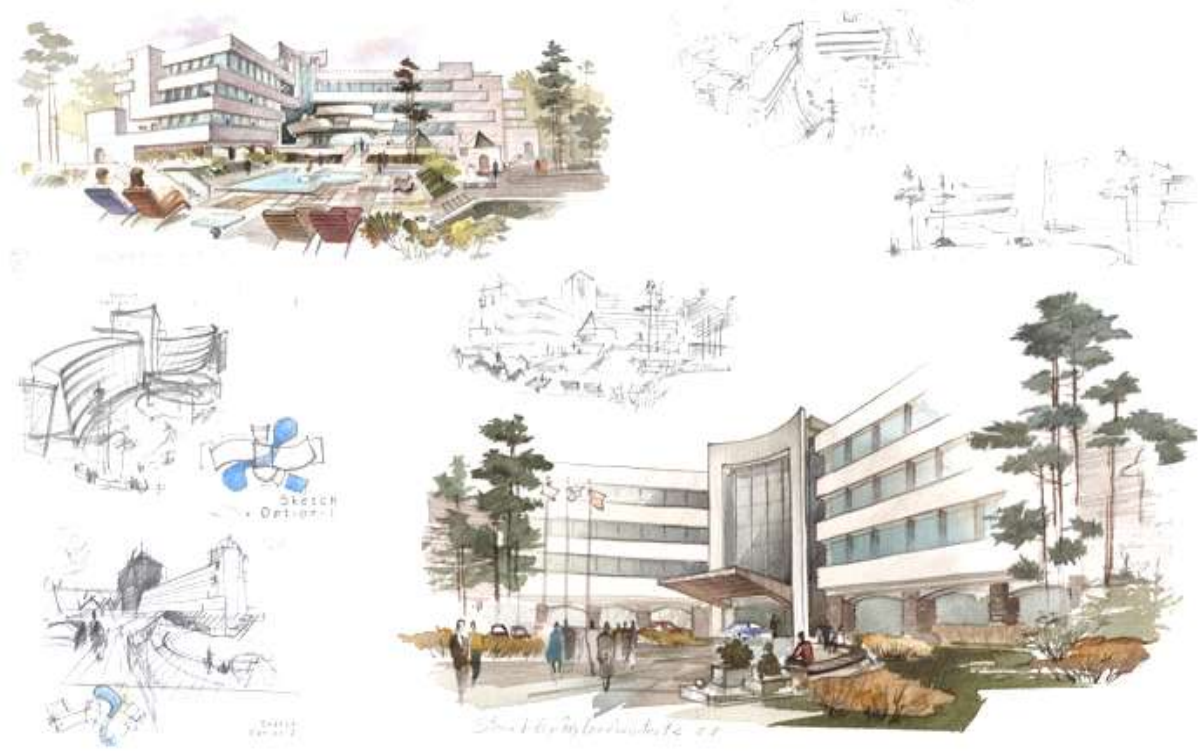

$$
\text { شكل(1): اسكتش يوضح استغلال الفراغات البينية في الاحتياجات الاجتماعية }
$$


• الاعتبارات البيئية في التصميم: المقصود بهذه العوامل هي العوامل المناخية التى يفرضها المناخ على مواد الإنشاء والتشكيل المعماري، وذلك بمراعاة عوامل الراحة الحرارية

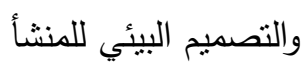
• الاعتبارات والمعايير الدولية والعالمية: ويعتمد التقييم البيئي للانظمه العالميه منل اللييد

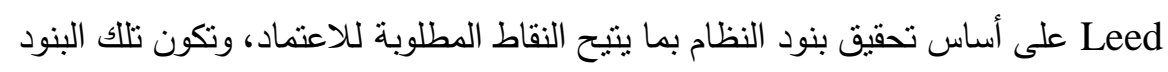

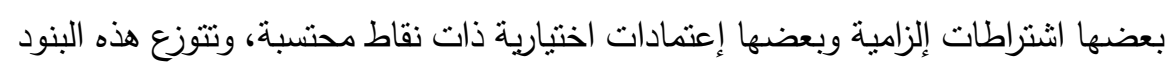

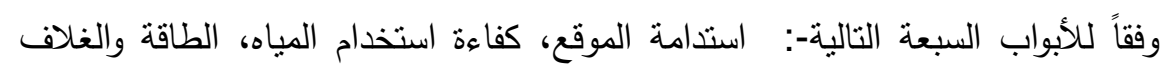

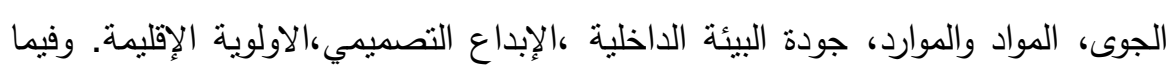

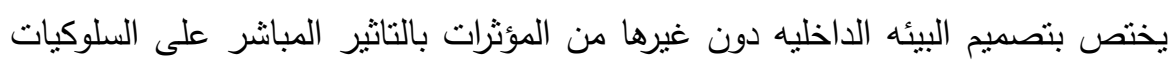
والاثر النفسي لتلبيه الاحتياجات النفسيه واشثباع الرغبات والاحتياجات الانسانيه والوظيفيه لثاغلي المبني • ويوضح نقاط النقييم لنظام الليبد للمباني من حيث جوده البيئه الداخليه

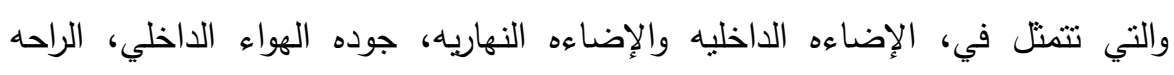
الحراريه، المواد منخفضه الانبعاثات، أداء الصوتيات، جوده المناظر والتي تؤثر بشكل الإهل

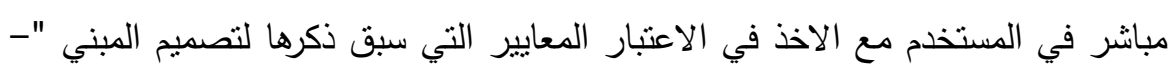

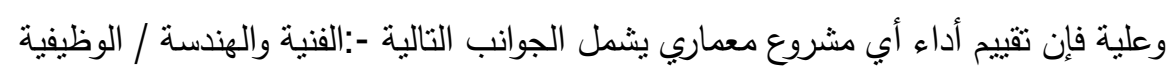

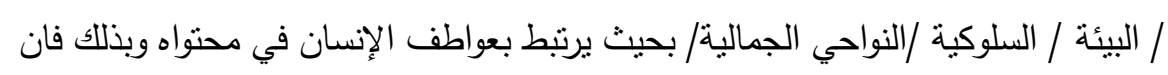

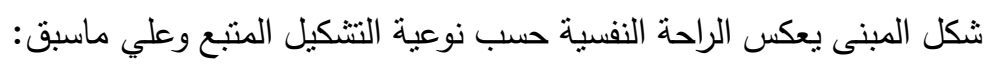

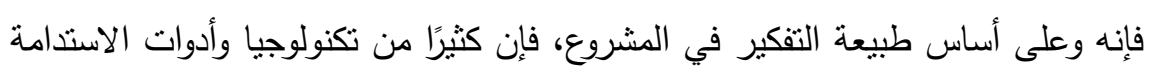

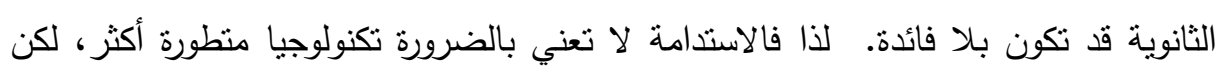

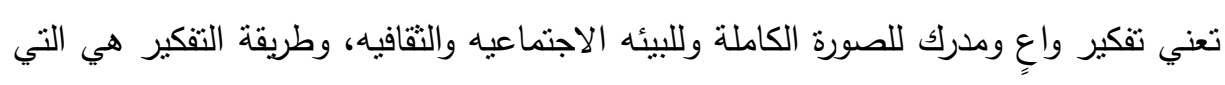
تحدد طريقة الاستدامة التي نسعى لها من خلال ( التصميم المتكامل للمباني)

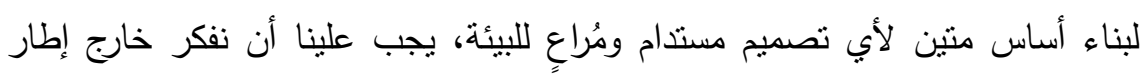

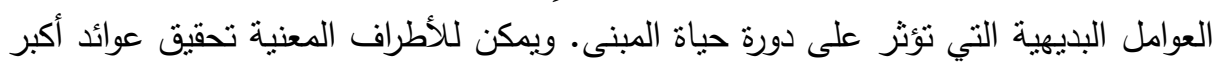

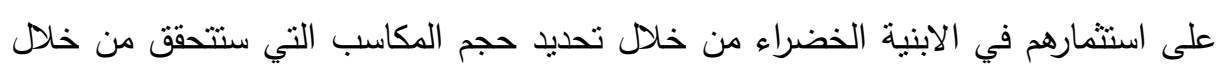
تحسن أداء مستخدمي المبنى بفضل( جودة وكفاءه البيئة الداخلية )

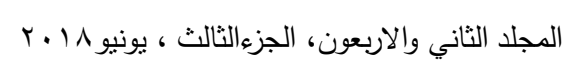


المعايير التي يمكن من خلالها تقييم جودة البيئة الداخلية خلال دورة حياه المبني: من خلال التحليل السابق يمكن الخروج بمجموعة من المعايير التي تضبط العلاقة بين تقييم جوده

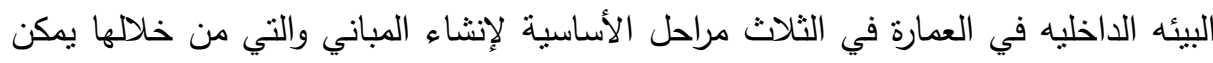
أن نقيم أدائها وبالتالي أداء المبنى وأثنره على البيئة

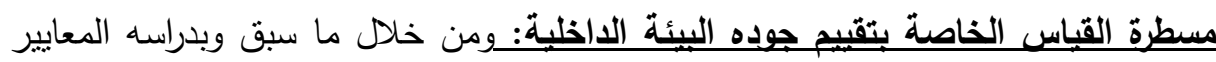
العالميه والاقليميه البيئيه والمعيار المصري نم ابتكار مسطرة قياس يمكن من خلالها قياس أداء كل من جوده البيئه الداخليه في العمارة

طريقة استخدام مسطرة القياس الخاصة بتقبيم جودة البيئة الداخلية: بعد الدراسة التحليلية والتركيز على العناصر التي تحقق أهداف البحث من دراسة جوده البيئه الداخليه تم ابتكار بـار مسطره قياس تتبع المعايير العالميه في جدول معايير تقييم للأداء فإذا حقق المبنى أحد نلك دلك

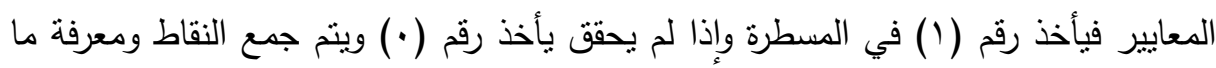
تمثله النقاط من إجمالي النقاط المطلوبة لكل من المادة والطاقة. 
جدول(1): مسطرة القياس الخاصة بتقييم جوده البيئه الداخليه

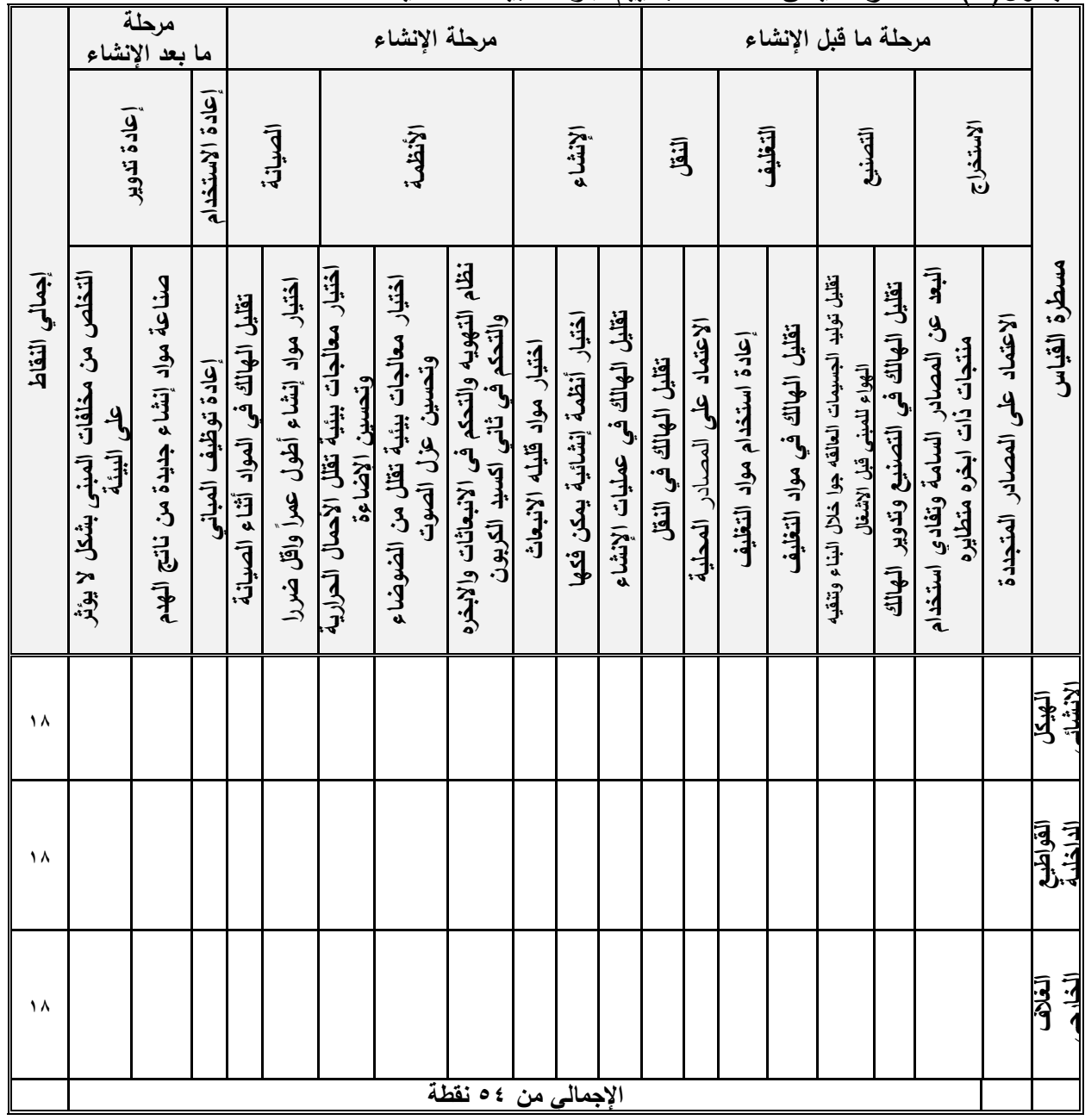

المصدر: الباحث

وصف أداة البحث: استخدم الباحث أيضاً نموذج الاستبانة كأداة رئيسية في جمع البيانات

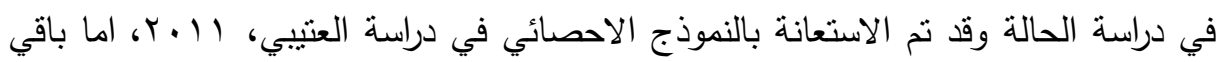

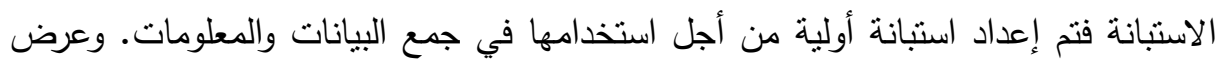
الاستبانة علي المشرف من أجل اختبار مدي وملاعمتها لجمع البيانات. كما نم تعديل

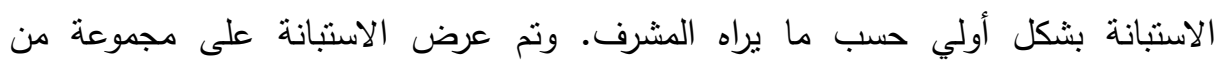

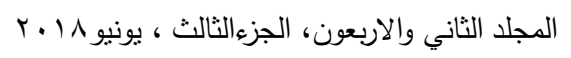


المحكمين والذين قاموا بدورهم بتقديم النصح والارشاد وتعديل وحذف ما يلزم. ثم تم توزيع

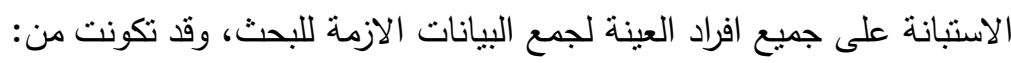

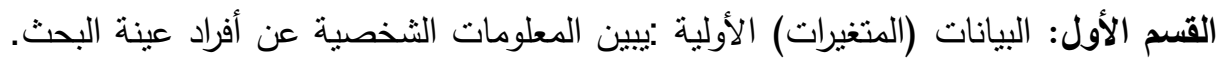

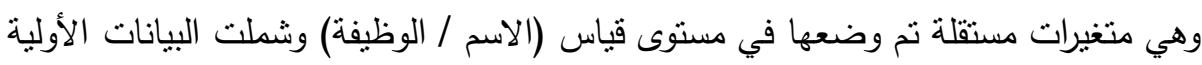

للعينة منل (العمر / الدرجه الوظيفيه / عدد سنوات الخبرة /المؤهل التعليمي....).

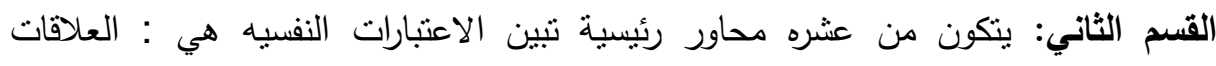

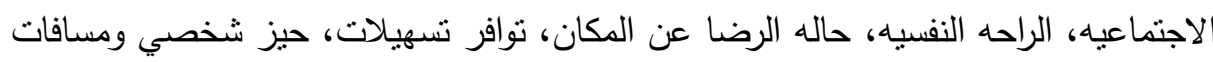

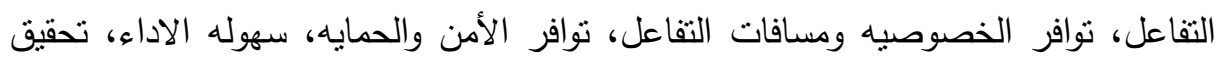
المكانه الوظيفيه، الترفيه والاستراحه، الجانب المنني والتخصصي لاعنبارات جودهات البيئه الداخليه المشيده

دراسة حالة لمشروع : المقر الرئيسي لبنك كريدي اجريكول بالقاهرة الجديدة

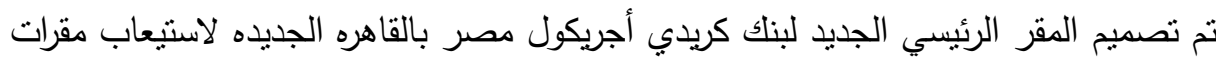

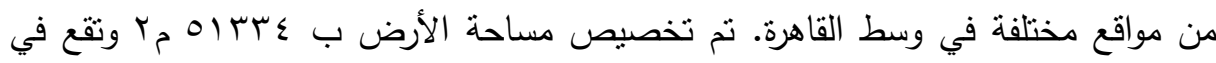

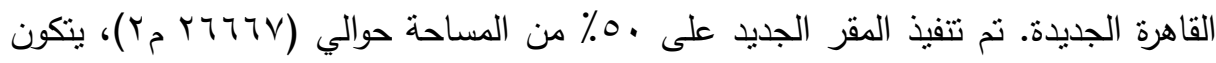
من عدد اثثين بدروم وطابق أرضي وثثلاثة أدوار متكررة.

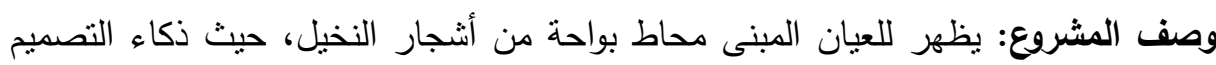
في استخدام موقع المشروع الطبيعي المتصف بالانحدار، وذلك لخلق أرضية حديقة شبه

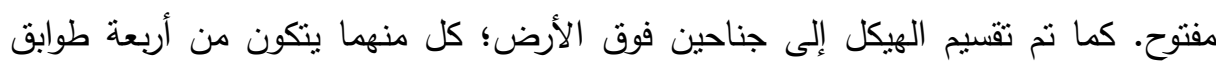
متصلة بواسطة القاعة المركزية من خلال الجسور الداخلية، واجهات المباني على درجة عالية

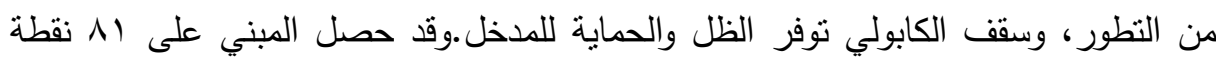

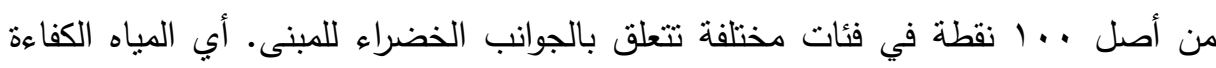
والطاقة والغلاف الجوي، والمواد والموارد وجودة البيئة الداخلية. 


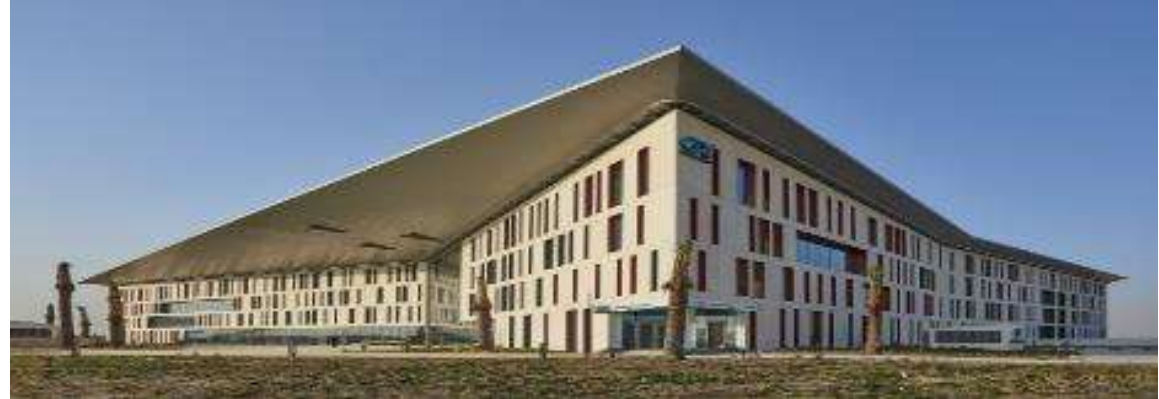

صوره رقم(1): المقر الرئيسي لبنك كريدي اجريكول القاهره الجديدة

أسس التصميم الرئيسية: MASTER PLAN CONCEPT

وضع في الاعتبار ثلاث غايات عندما تم التخطيط الرئيسي:

• حضور قوي للمبني كعلامة مميزة بالبيئة المحيطة

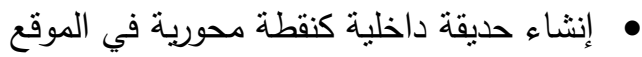

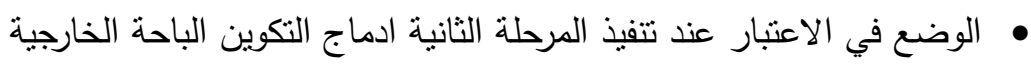

الاستراتيجيات المتعلقة بالفراغات والكتل:

\begin{tabular}{|c|c|}
\hline 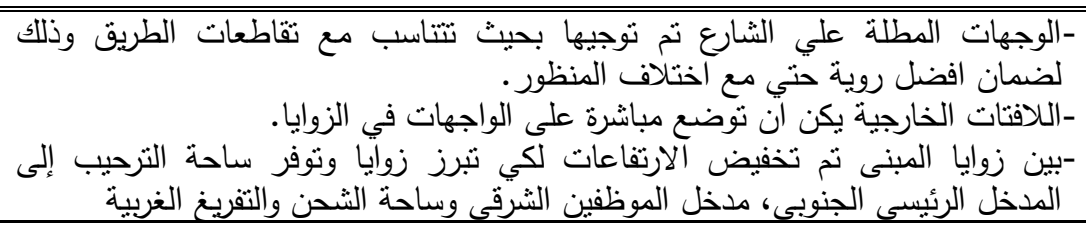 & الواجهات \\
\hline 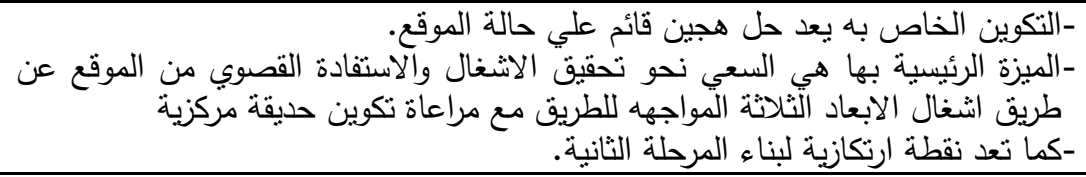 & والحداحقه \\
\hline 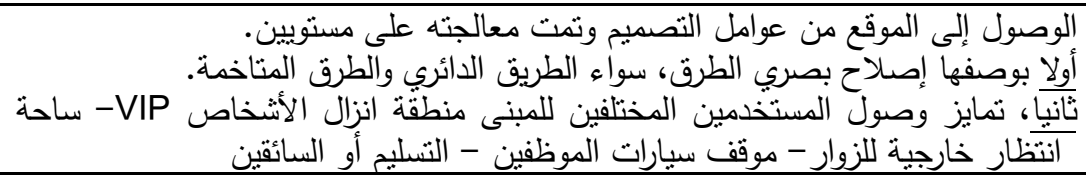 & التوائية \\
\hline 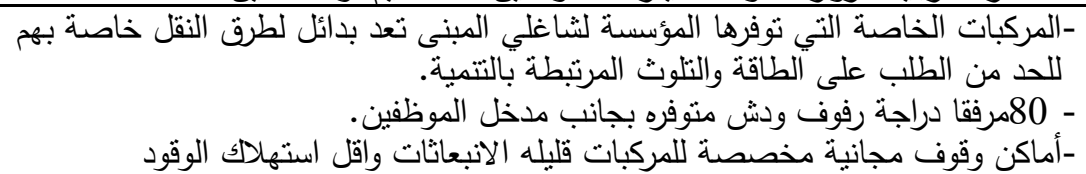 & البنقل \\
\hline
\end{tabular}




\section{تابع: الاستراتيجيات المتعلقة بالفراغات والكتل:}

\begin{tabular}{|c|c|}
\hline 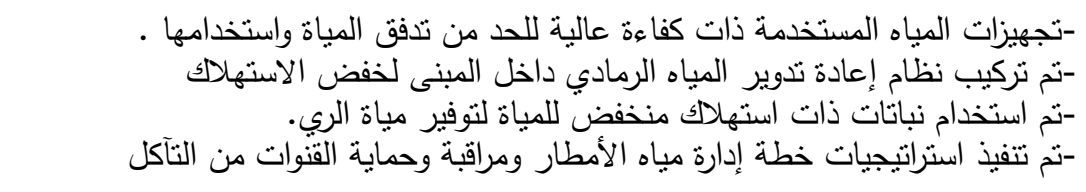 & الماء \\
\hline 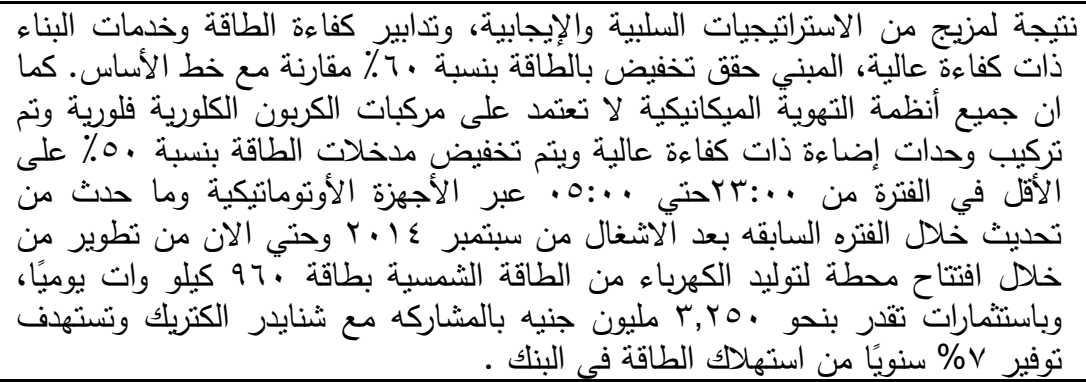 & الطاقة \\
\hline 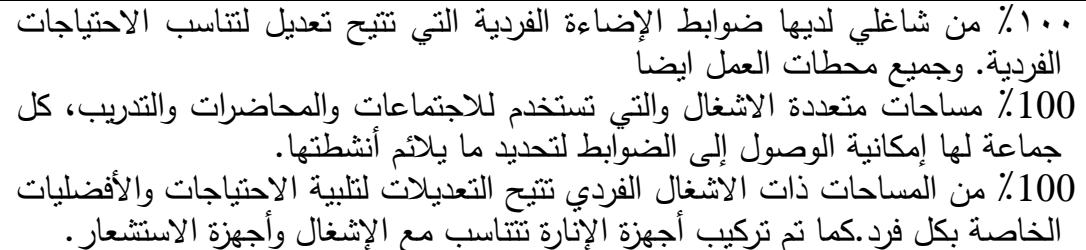 & ألاضاءة \\
\hline 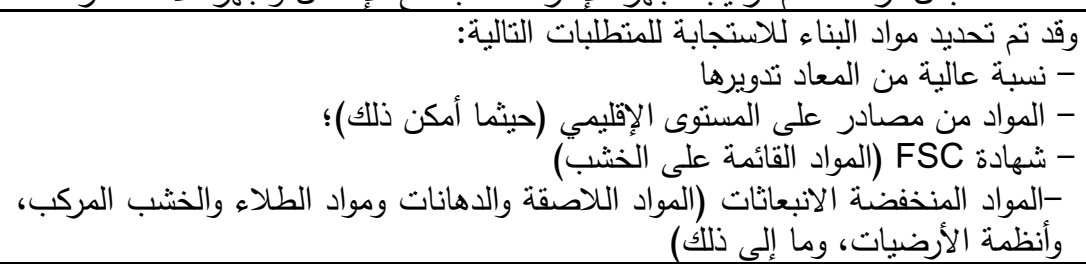 & البناء \\
\hline
\end{tabular}

مميزات الاستدامة بالمبني محل الدراسة: لقد نم استخدام آلية توضح مدى كفاءة المبني للمقارنة بين المعايير المختلفة حيث تم استعمال مسطره القياس لتحديد مدي موائمه المبني وتوافقه مع الاعتبارات البيئيه والاكواد الخضراء وتحقيق الاعتبارات الانسانيه والاحتباجات مريه النفسيه لثناغلي المبني 


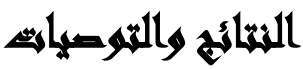

خلصت الورقة البحثية إلى تحديد بعض النتائج في النقاط الهامة التالية:

ا. يعتبر تحقيق تعايش الإنسان مع محيطه من خلال المبنى هي وظيفه المعماري وتتخطي

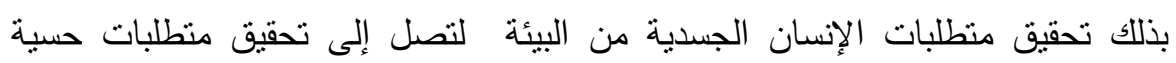
ووجدانية مرنبطة بالمثل بالبيئة.

r. يساعد تضمين الظواهر الطبيعية في المبنى إلى جانب التأثير في الحواس على بلى ربط مواد محلية فقط بل بشعور الأفراد كونهم جزء من تللك البيئة ومتغيراتها المحلية المختلفة،

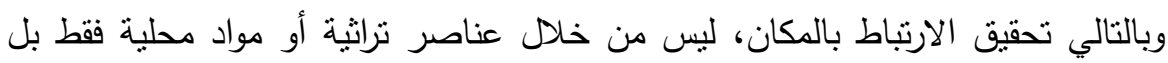

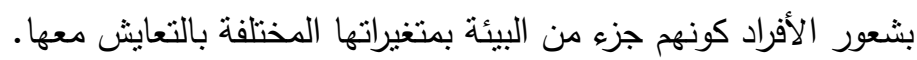
r. التصميم هو هوية معبره للتفاعل المشترك والمتكامل ويحقق احتياجات شاغليه ويراعي

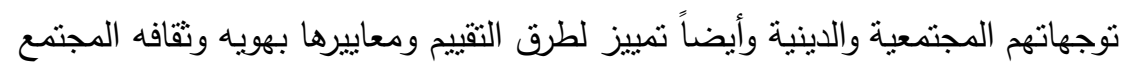
وقد خلص البحث الى بعض التوصيات: وعليه نوصى الدراسة في دور كلا من: المؤسسات التعليمية والاكاديمية: 1- تتميه ثقافه الحفاظ على البيئه الطبيعيه والبيئه المشيده لتحقيق عناصر الاثباع للحاجات الاساسيه ( الراحه الحراريه - البصريه والنفسيه ) للاجيال الحاليه والقادمة. r- ودعم المناهج التعليميه لدارسي المهن الهندسيه بالاكواد البيئيه والمعايير المحليه اللازميه

$$
\text { اللمؤسسات والجهات المسئوله في الدوله فترات الدراسه ( خمس سنوات ). }
$$

ا - دعم التشريعات والقوانين واللوائح لدعم لتنفيذ الأكواد الخضراء مع وجود سياسات الزاميه للمستثرين للبناء بالحد الأدني الإلزامي من البناء الاخضر وفترات البترات زمنيه الزاميه محدده

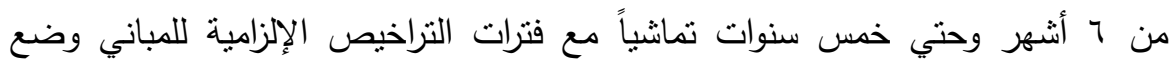

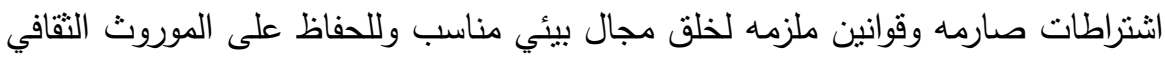

$$
\text { المصري والهويه المعماريه. }
$$

r-سياسات تشجيعيه من الدوله مع ايجاد آليات للنطبيق والتتسيق بين الجهات المسئوله السياسات التحفيزيه من متخذى القرار لاعم الاتجاه البيئي في التصميم والتتغيل لاركان

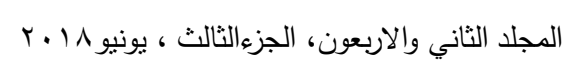


العمليه التصميمه وذلك للتوجيه والارشاد البيئي وزياده الطلب على الجوانب البيئيه

ومتطلباتها والاعتبارات الدوليه والعالميه وما يناسبها للبيئه المصريه من حيث النطبيق.

\section{المرائs}

أحمد معوض عوض(0 . . ؟): الواقع الافتراضي في التصميم المعماري. الثورة الرقمية وتأثنرها

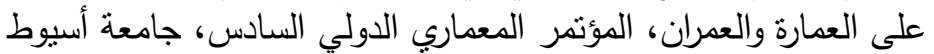

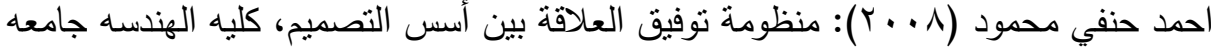

القاهرة

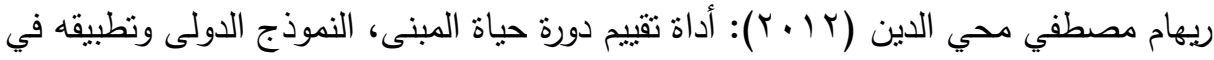
مصر ، رسالة دكتوراه، كليه الهندسه، جامعه القاهرة

Ahmed Omar Mohamed(2009): An approach to activate the application of concept of (sustainable building) through the methodology of( value Engineering and ( life cycle costing) - Cairo uni

Shady Attia, LEED®(2011): State of the Art of Existing Early Design Simulation Tools for Buildings: A Comparison of Ten Tools Université catholique de Louvain,Louvain La Neuve, Belgium 


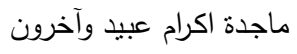

\title{
BUILDING EVALUATION ACCORDANCE WITH ENVIRONMENTAL STANDERDS CASE STUDY - CREDE AGRICOLE BANK
}

Ebeid, Magda, E. ${ }^{(1)}$; El- Attik, A. M. ${ }^{(1)}$ and Ahmed, K. T. ${ }^{(2)}$

1) Institute of Environemnt Studies and Research, Ain Shams University 2) Architectureal Sector, Sabbour consulting bureau .

\begin{abstract}
The importance of architecture sustainable environmental in our modern life, where it became the future of architecture in general, and here Assessing the extent of success in achieving its objectives is a necessary and very important for the evolution for the better agrees needs environment Egyptian society, hence the importance of assessing the level of performance of buildings practically and objective does not depend on the caprices or personal preferences, but must first be integrated assessment and in accordance with the local environment of the Egyptian society without neglecting the requirements of architecture, such as aesthetics, construction and humanitarian and social needs without neglecting the international environmental standards.

Research problem that architectural have set of problems most important of the absence of information and lack of knowledge of how to measure the efficiency of design and evaluate its performance within the framework of a scientific and objective appropriate to the local environment, which helps to reach levels high of performance and find out what the shortcomings and successes in previous attempts under all these global design standards

The study is divided into two parts theoretical and practical. Theoretical part begins by addressing:
\end{abstract}

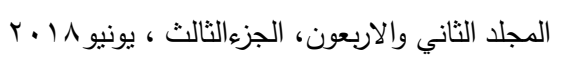


First: where are most of the literature review of letters and books and magazines predecessor on the subject of scientific research, and to support research methodology references and scientific theories.

second: And where is the application of the basics and the different standards of theoretical study on some buildings and environmental projects in Egypt, and to measure the efficiency of the proposed approach and to determine the relative importance of the elements of this approach to improve the efficiency in buildings and determine the availability of components approach in the models under study through design questionnaire the survey from those standards and as much treatment and its impact on buildings and to achieve social and cultural needs

the main objective of this study raise the efficiency of the product architecture and sustainable through emphasis on the importance of sustainable development in its comprehensive concept and that where achieved sustainable architecture of sustainable development goals and also reflects inaction negative effects on many development path, so Studying elements and elements of sustainable architecture seems already necessary to get to the product architect environmentally harmonious and homogeneous helps to achieve comprehensive development in the light of the social and cultural needs of the Egyptian society.

Key Words :Enviromental Ratin Sysetem - environmental Standards Sustinable Architecture - Psychological Dimensions in Design 